\title{
Activation of MAP kinases by green leaf volatiles in grasses
}

\author{
James E. Dombrowski* and Ruth C. Martin
}

\begin{abstract}
Objective: Previously we have shown that mechanical wounding and volatiles released from cut grass, activated a 46 and $44 \mathrm{kDa}$ mitogen-activated protein kinase (MAPK) in the model grass species Lolium temulentum (Lt). MAPKs play an important role as signal relays that connect incoming stress signals and stress responses. Since green leaf volatiles (GLV) are released during wounding, we wanted determine if specific compounds contained in the GLV mixture or if GLV generated from other plant species could activate these Lt MAPKs.

Results: Our analysis found that just a 1-min exposure to GLV was enough to activate the Lt $46 \mathrm{kDa}$ MAPK within $3 \mathrm{~min}$ and the $44 \mathrm{kDa}$ MAPK within $15 \mathrm{~min}$. This activation pattern showed similar kinetics to those observed after wounding, and the GLV and wound activated bands associated with these MAPKs displayed identical migration on sodium dodecyl sulfate polyacrylamide gels. Thirteen different commercially available plant volatiles (alcohols, aldehydes and ketones) were tested and all thirteen volatile compounds were able to activate these same Lt MAPKs. Furthermore, GLV derived from three other grass species as well as tomato, a dicot, were also shown to activate these MAPKs in $L t$.
\end{abstract}

Keywords: Grass, Green leaf volatiles, Kinases, Lolium, MAPK, Volatiles, Wounding

\section{Background}

Plants in the field are faced with a variety of stresses on any given day. They must sense their environment, allocate and prioritize available resources to mobilize a coordinated response to alter their physiological and metabolic state in order to survive. Plants have evolved a variety of interconnected signaling networks and mechanisms to respond to these various types of stresses [1-3]. One of the major stresses forage and turf related grasses are subjected to is wounding. Unlike cereal grasses and many other crop species, forage and turf grasses are repeatedly cut or grazed upon throughout their lifecycle. Currently there is very little known concerning the perception, signalling or molecular responses associated with wound stress in grasses. When grasses are cut or damaged, they rapidly release a volatile chemical cocktail called green leaf volatiles (GLV) [4]. GLV and other plant volatiles have been shown to play a role in plant defense

*Correspondence: Jim.Dombrowski@ars.usda.gov

USDA-ARS, National Forage Seed Production Research Center, 3450 SW Campus Way, Corvallis, OR 97331-7102, USA against insects and pathogens [5-9] and have been implicated to have a role in abiotic stress responses [9-11]. Furthermore GLV may prime or enhance the plant's response to particular stresses and this priming effect may occur via inter- and/or intra-plant signalling $[8,9$, 12-17].

Previously we found that mechanical wounding in six different grass species activated a 46 and $44 \mathrm{kDa}$ mitogen-activated protein kinase (MAPK). The $46 \mathrm{kDa}$ MAPK was found to be rapidly activated both locally and systemically in an adjacent unwounded tiller within 5 min of wounding in the model grass species Lolium temulentum $(L t)$ [18]. Similarly when leaf tissue was damaged by nonanoic acid, a nine-carbon-chain carboxylic acid used in grass herbicides, the $46 \mathrm{kDa}$ MAPK was activated in the treated leaves within $5 \mathrm{~min}$ of exposure and in undamaged systemic tissues within $15 \mathrm{~min}$ [19]. Furthermore damaged caused by fire to $L t$ tiller leaf tips, activated both the 46 and $44 \mathrm{kDa}$ MAPKs within 5 and 20 min respectively, and within 15 min in the systemic undamaged tiller [19]. 
MAPK signaling cascades have been shown to play a significant role in the regulation of defense, stress and developmental related pathways [20-22]. In response to a specific stress or environmental stimuli, MAPK signaling cascades, acting as an integral component of a coordinated signaling network, lead to the activation of specific downstream targets to elicit a stress specific response $[22,23]$. The rapid activation of these MAPKs to multiple types of stresses in forage and turf grasses suggest that they play a significant role in the perception and response to these stresses $[18,19,24]$. Surprisingly in our investigation of the stress activation of MAPKs in $L t$, we found that GLV released from grass clippings activated both the 46 and $44 \mathrm{kDa}$ MAPKs [19]. The similar kinetics of activation of these MAPKs by GLV and by direct mechanical wounding indicate a potential role for these volatile compounds in wound signaling in forage and turf grasses.

In this manuscript we extend these studies to determine minimal exposure time necessary for GLV activation of the MAPKs. Additionally we tested 13 commercially available compounds associated with GLV to determine if a specific compound or class of compounds could activate the MAPKs. Lastly, we investigated if GLV from different plant species could activate the $L t$ MAPKs.

\section{Main text}

\section{Methods}

\section{Plant materials}

Lolium temulentum L. (Lt, Darnel ryegrass) cv. Ceres seeds were planted in 36 well flats, $2 \times 1.5 \times 2$ in. well $(1$ plant/well) containing either Professional Growing Mix MM840 PC RSi or LA4 PC RSi (Sungro Horticulture, Canada). Plants were grown under $12 \mathrm{~h}$ photo-periods at $23{ }^{\circ} \mathrm{C}$ day and $18{ }^{\circ} \mathrm{C}$ night in Conviron E15, PGR15, PGV36 or PDW40 (Conviron, Winnipeg, Canada) growth chambers. Tissues used to generate GLVs were taken from Lt, Brachypodium distachyon, tall fescue, orchardgrass and tomato (cv Castlemart) plants grown from seed in $1 \mathrm{~L}$ pots in a greenhouse $\left(24-28^{\circ} \mathrm{C}\right.$ day and $18{ }^{\circ} \mathrm{C}$ night). Plants were fertilized weekly using Jack's Professional General Purpose 20-20-20 fertilizer (JR Peters Inc, USA).

\section{Stress treatments}

$L t$ receiver plants were grown in individual wells in flats in a growth chamber for 3-4 weeks. When the plants reached the two/three-tiller stage, the individual wells/ pots were separated and the plants allowed to rest overnight prior to treatment.

Wounding of $L t$ plant was performed as described [18].

Green leaf volatiles: Lt, Brachypodium, tall fescue, orchardgrass or tomato leaf cuttings were placed on the bottom (approximately $0.5-1 \mathrm{in}$. deep) of three $8.3 \mathrm{~L}$ Nalgene multipurpose polycarbonate jars with covers (non air tight). The 1-2 in. long cuttings were crushed by hand and placed into the cylinders (with lids). Plants were exposed to vapors of 13 different volatile compounds (see Fig. 2a) by pipetting 10 or $25 \mu \mathrm{L}$ of the compound onto a Q-tip in the cylinder. The cylinders containing the plant leaf clippings or volatile compounds were placed into a growth chamber under light for 5 min before adding plants. Into each cylinder three $L t$ plants were placed. The plants were treated and removed from the cylinders as previously described [19] at the time points indicated: Cylinder \#1 time points 3,15 and $30 \mathrm{~min}$; Cylinder \#2 time points 5, 20 and $45 \mathrm{~min}$; Cylinder \#3 time points 10, 25 and $60 \mathrm{~min}$. The time course for the control plants was performed as described above except there were no grass clippings in the cylinders. Note for the 1 min exposure experiment, $L t$ plants were placed into the 3 cylinders as described above for only $1 \mathrm{~min}$ and then immediately removed from the cylinders. The cylinders containing the clippings were removed from growth chamber, while the plants remained in the chamber for the remainder of the time course. All plant tissues were collected, quick frozen with liquid nitrogen and stored at $-80{ }^{\circ} \mathrm{C}$ until processed. Sample preparation and immunoblot analysis was performed as described previously $[18,19,24]$ and loading controls (Additional file 1: Figure S1).

\section{Results}

This study expanded the analysis of GLV and their ability to activate MAPK signaling cascades in the model grass species $L t$. Previously mechanical wounding was shown to rapidly activate a 46 and $44 \mathrm{kDa}$ MAPK in $L t$ [18]. Similarly, exposure of $L t$ to freshly mowed grass clippings was also shown the activate MAPKs with similar kinetics [19]. The activation of the 46 and $44 \mathrm{kDa}$ MAPKs in $L t$ by wounding and continuous exposure to GLV is shown in Fig. 1a. Interestingly, it takes only 1 min exposure to GLV from cut grass clippings to activate the MAPKs. The migration of the bands for the 46 and $44 \mathrm{kDa}$ MAPK activated by wounding and GLV appear to be the same (Fig. 1b). Additionally, we investigated whether antibodies (Sigma, USA) to the Arabidopsis AtMPK3, AtMPK4 or AtMPK6, which have been shown to be involved in stress responses [25], would cross react with the $L t 46$ or $44 \mathrm{kDa}$ MAPK bands. While all 3 antibodies displayed cross-reactive bands in $L t$, and the antibodies to AtMPK4 or AtMPK6 identified bands with very similar migration to the $L t$ anti-phospho-MAPK (Erk1/2) $46 \mathrm{kDa}$ band, but they did not appear to be the same (data not shown).

GLV contain a wide range of volatile compounds $[4,26$, 27], therefore we wanted to determine if a specific compound or class of compounds activated the $L t$ MAPKs. Thirteen commercially available compounds, many found in GLV [4], from 3 different chemical classes, aldehydes, 


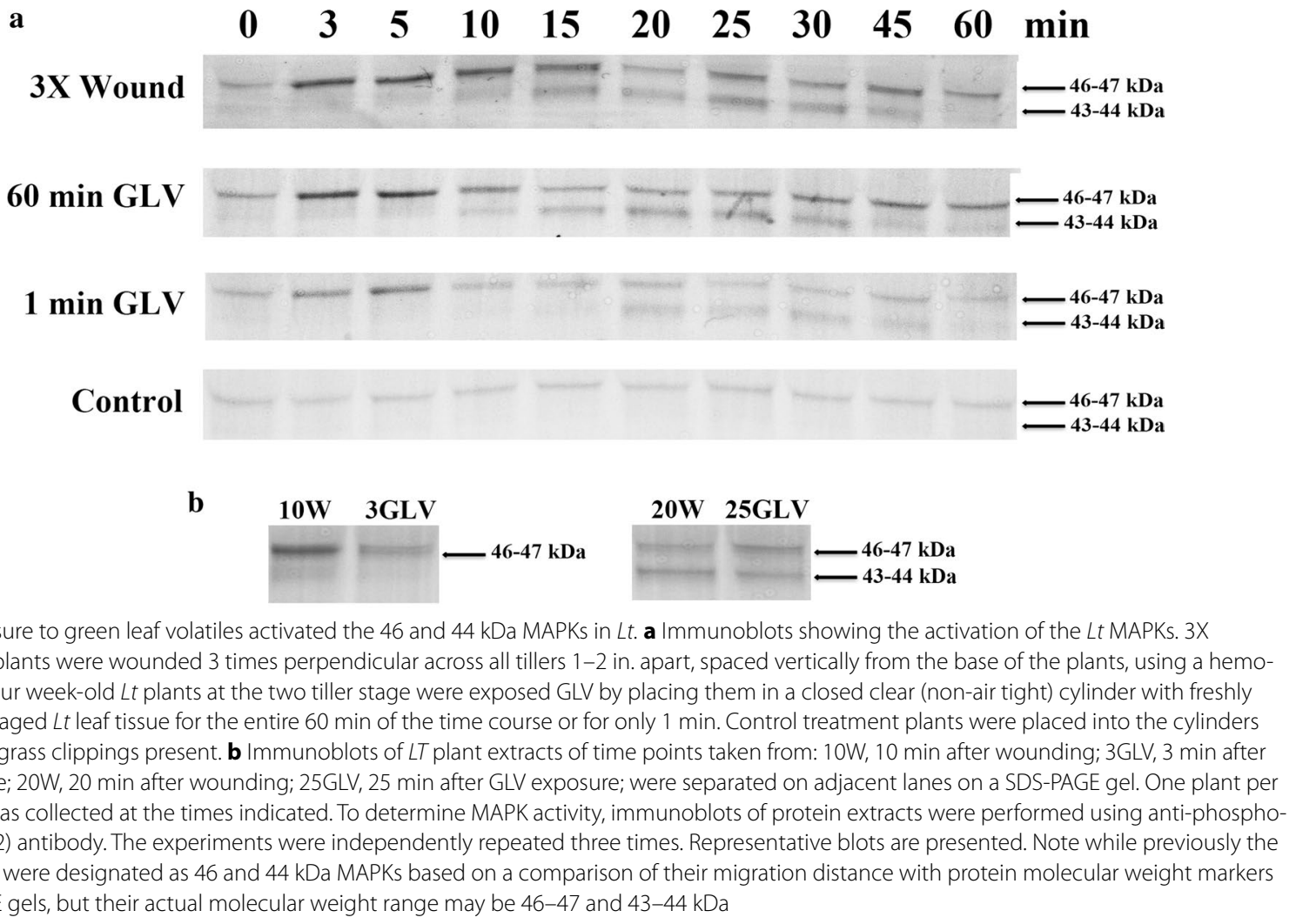

alcohols and ketones were tested. Surprisingly all of the compounds tested (Fig. 2a) activated both the $L t 46$ and $44 \mathrm{kDa}$ MAPKs with some variation in kinetics. It should be noted that no significant differences for MAPKs activation were observed whether 10 or $25 \mu \mathrm{L}$ of the compound was used. Since all the compounds activated both the 46 and $44 \mathrm{kDa}$ MAPKs, and many of these compounds are present in other GLV released from other plant species, we wanted to see if other plant GLV could activate the MAPK in $L t$. As shown in Fig. 3, when $L t$ was exposed to GLV from the orchardgrass and tall fescue forage grasses, the model grass Brachypodium or from the dicot tomato, all were found to have activated both the 46 and $44 \mathrm{kDa}$ MAPK. For all specific GLV compounds and different plant species GLV tested, the $L t 46 \mathrm{kDa}$ MAPK was activated within 3-5 min of exposure, and the $L t 44 \mathrm{KDa}$ MAPK was activated after 15-25 min of exposure.

\section{Discussion}

Plants utilize a variety of compounds to respond to their environment. In recent years volatile compounds have been implicated to have a role in a wide range of stresses. In this report we investigated further the activation of stress related MAPKs $[18,19,24]$ in the model grass $L t$ by plant volatiles. For a signal to be effective it must be perceived in a short time and initiate a rapid response. Our analysis found that just a 1-min exposure to GLV was enough to activate the $L t 46 \mathrm{kDa}$ MAPK within $3 \mathrm{~min}$ and the $44 \mathrm{kDa}$ MAPK within $15 \mathrm{~min}$. This activation shows similar kinetics to those observed after wounding, and the GLV and wound activated bands associated with these MAPKs had nearly identical migration on sodium dodecyl sulfate polyacrylamide gel electrophoresis (SDS-PAGE). Our analysis also found that 13 different commercially available plant volatiles, many of which were found to be released by tufted hairgrass after mechanical wounding [4], were also able to activate these same MAPKs. Furthermore, GLV derived from three other grass species as well as tomato, a dicot, were also able to activate these MAPKs. These results indicate that this MAPK activation is a generalized response to the release of volatiles associated with plant damage. However, not all plant derived volatiles associated with the plant's wound response activated these MAPKs. Previously, we showed that the direct exposure of $L t$ plants to the volatile signaling molecule methyl jasmonate (MJ) did not activate the 46 and $44 \mathrm{kDa}$ MAPKs, however when plants were exposed to MJ prior to wounding, it did enhance the wound activation of the $44 \mathrm{kDa}$ MAPK [18]. Synergistic effects between GLV and jasmonic acid have 


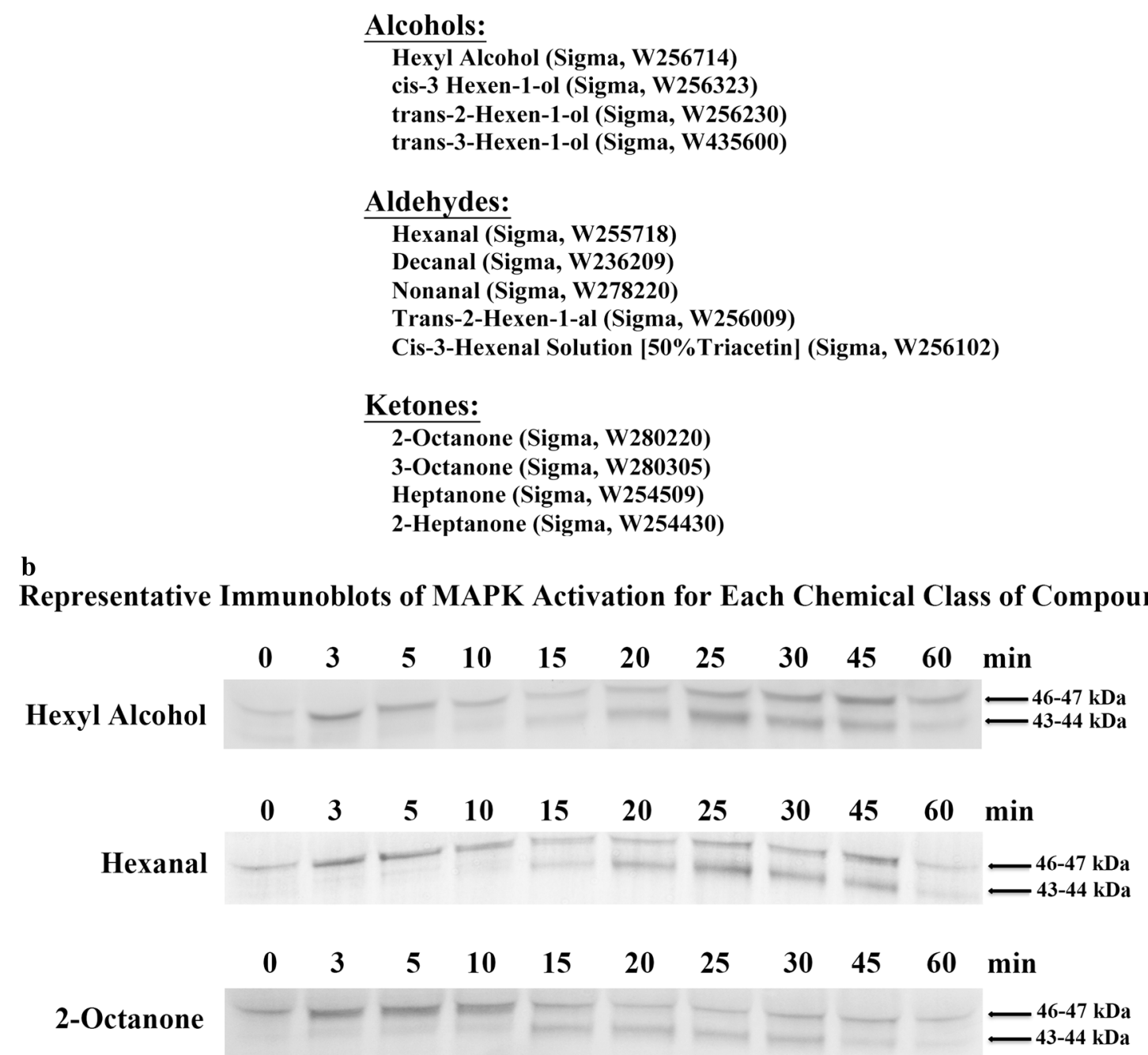

Fig. 2 Plant volatile compounds activated the $L t 46$ and $44 \mathrm{kDa}$ MAPKs. a A list of 13 plant volatile compounds separated into different chemical groups (alcohols, aldehydes and ketones) that were tested for their ability to activate the Lt 46 and 44 kDa MAPKs. Chemical name (company, catalog number). b Representative immunoblots of MAPK activation for one member of each chemical class of compounds are presented. Plants were exposed to vapors of each individual volatile compound by pipetting $10 \mu \mathrm{L}$ of the compound onto a Q-tip in the cylinder, and then 3-4 week-old Lt plants at the two tiller stage were placed into a closed clear (non-air tight) cylinder. One plant per time point was removed from the cylinder and collected at the times indicated. Note control treatment plants were placed into the cylinders without addition of a volatile compound-see Fig. 1. To determine MAPK activity, immunoblots of protein extracts were performed using anti-phospho-MAPK (Erk1/2) antibody. The experiments were independently repeated three times per compound

been observed in other plant species [28]. Furthermore $L t$ plants treated with linolenic acid, the precursor to JA were unable to activate either MAPK [19]. The GLV and volatile compounds released by plants after damage may be involved in both inter- as well as intra-plant signaling. In the field plants are often being exposed to below threshold levels of volatile compounds for activation of a stress response. However this intermittent low level exposure may prime or sensitize the plant, providing a more rapid and robust response towards potential future stresses $[8,9,12-17]$. The ability of grasses to perceive these compounds in their surrounding environment and to prime the plant's response for the potential oncoming wound stress could be advantageous for grasses, which are routinely cut and grazed upon throughout their lifecycle. While other types of signals, such as reactive oxygen species [29, 30], are used for intra-plant signaling to undamaged systemic tissue, volatile compounds have been implicated to play a more significant role in plant species with less developed vascular systems [31]. The 


\section{$\begin{array}{llllllllllll}0 & 3 & 5 & 10 & 15 & 20 & 25 & 30 & 45 & 60 & \mathbf{m i n}\end{array}$ Tall Fescue GLV - - - $-46-47 \mathrm{kDa}$

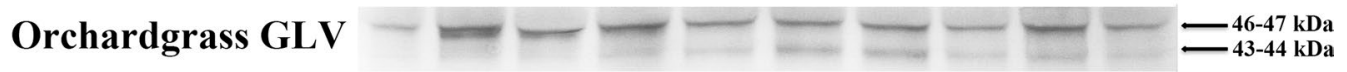 Brachypodium GLV - - - $\square-\square={ }_{43-44 \mathrm{kDa}}^{46-47 \mathrm{Da}}$ Tomato GLV

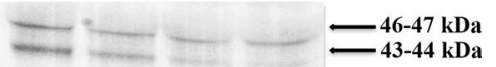 \\ Fig. 3 GLV generated from other plant species activated the $L t 46$ and 44 kDa MAPKs. Three-four week-old $L t$ plants at the two tiller stage were placed into a closed clear (non-air tight) cylinder with freshly cut and damaged leaf tissue from plants indicated in the figure. One plant per time point was collected at the times indicated. Note control treatment plants were placed into the cylinders without any grass clippings present-see Fig. 1. To determine MAPK activity, immunoblots of protein extracts were performed using anti-phospho-MAPK (Erk1/2) antibody. The experiments were independently repeated three times. Representative blots are presented}

data presented in this report suggests links between GLV and wound signaling. Future research will be directed at determining what downstream elements are being activated by exposure to GLV and wounding, how they are connected, and how the plant responds at the molecular or physiological level to these different stimuli.

\section{Limitations}

Concentration curves for the various commercially available compounds for MAPK activation were not done. Since so many compounds were tested, it made it extremely difficult to directly compare intensity of MAPK activation between samples, however kinetics (timing) of the activation the 46 and $44 \mathrm{kDa}$ MAPKs was possible. The actual concentrations of GLV in the field that forage or turf grasses are exposed to when they are cut, as in a lawn or for collection of hay, are unknown. However cut grass will release high levels of GLV that can be detected at great distances suggesting that in localized areas GLV concentrations could approach those used during our experiments.

\section{Additional file}

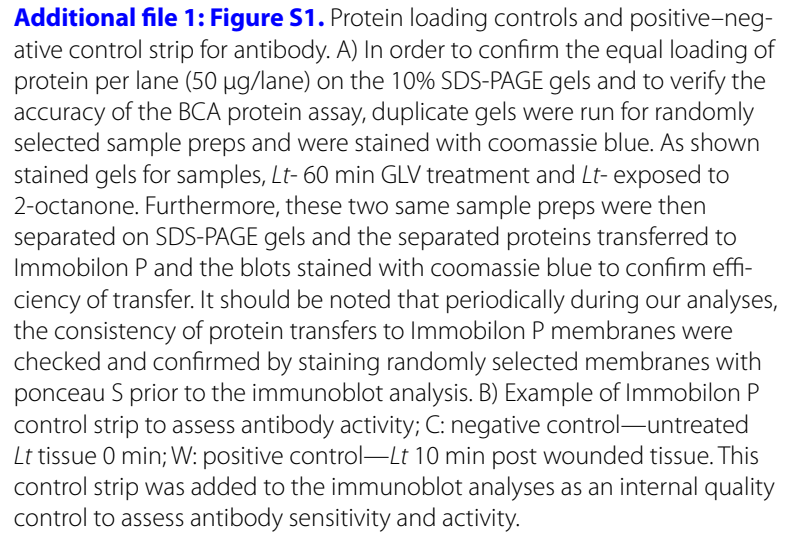
ative control strip for antibody. A) In order to confirm the equal loading of protein per lane (50 $\mathrm{\mu g} / \mathrm{lane}$ ) on the 10\% SDS-PAGE gels and to verify the accuracy of the BCA protein assay, duplicate gels were run for randomly selected sample preps and were stained with coomassie blue. As shown stained gels for samples, $L t-60$ min GLV treatment and $L t$ - exposed to 2-octanone. Furthermore, these two same sample preps were then separated on SDS-PAGE gels and the separated proteins transferred to Immobilon P and the blots stained with coomassie blue to confirm efficiency of transfer. It should be noted that periodically during our analyses, the consistency of protein transfers to Immobilon P membranes were checked and confirmed by staining randomly selected membranes with ponceau S prior to the immunoblot analysis. B) Example of Immobilon P control strip to assess antibody activity; C: negative control—untreated $L t$ tissue 0 min; W: positive control— $L t 10$ min post wounded tissue. This control strip was added to the immunoblot analyses as an internal quality control to assess antibody sensitivity and activity.

\section{Abbreviations}

ERK: extracellular signal regulated kinase; GLV: green leaf volatiles; JA: jasmonic acid; Lt: Lolium temulentum; MAPK: mitogen-activated protein kinase; MJ: methyl jasmonate; PAGE: polyacrylamide gel electrophoresis; SDS: sodium dodecyl sulfate.

\section{Authors' contributions}

JED and RCM conceived of the study and participated in its design. JED performed the experiments. JED and RCM drafted the manuscript. Both authors read and approved the final manuscript.

\section{Acknowledgements}

Special thanks is extended to Dr. Lloyd T Evans (CSIRO, Canberra Australia) for his generous gift of the Lolium temulentum cv. Ceres seed. Experimental methods performed in this research complied with current laws and regulations of the USA. The use of trade, firm, or corporation names in this publication is for the information and convenience of the reader. Such use does not constitute an official endorsement or approval by the United States Department of Agriculture or the Agricultural Research Service of any product or service to the exclusion of others that may be suitable.

\section{Competing interests}

The authors declare that they have no competing interests.

\section{Availability of data and materials}

Data: Not applicable.

The seeds for the plant material used in this research are publically available and can be obtained from either the United States Department of Agriculture-Agricultural Research Service National Plant Germplasm System or by contacting the corresponding author.

\section{Consent for publication}

Not applicable.

\section{Ethics approval and consent to participate}

The research presented in this manuscript was conducted by scientists from the United States Department of Agriculture-Agricultural Research Service and approved by the Research Leader of the Forage Seed and Cereal Research Unit. All experiments conducted comply with United States Government federal law and complies with regulations under the State of Oregon. USDA-ARS Project No: 2072-21000-045-00D.

\section{Funding}

Funding for this research was provided by the United States Department of Agriculture-Agricultural Research Service; National Program 215: Pasture, Forage and Rangeland Systems; Project No: 2072-21000-045-00D. 


\section{Publisher's Note}

Springer Nature remains neutral with regard to jurisdictional claims in published maps and institutional affiliations.

Received: 4 October 2017 Accepted: 8 December 2017

Published online: 29 January 2018

\section{References}

1. Fujita M, Fujita Y, Noutoshi Y, Takahashi F, Narusaka Y, Yamaguchi-Shinozaki K, Shinozaki K. Crosstalk between abiotic and biotic stress responses: a current view from the points of convergence in the stress signaling networks. Curr Opin Plant Biol. 2006:9(4):436-42.

2. Krasensky J, Jonak C. Drought, salt, and temperature stress-induced metabolic rearrangements and regulatory networks. J Exp Bot. 2012:63:1593-608.

3. Chinnusamy V, Schumaker K, Zhu J-K. Molecular genetic perspectives on cross-talk and specificity in abiotic stress signalling in plants. J Exp Bot. 2004;55:225-36

4. Watkins E, Gianfagna TJ, Sun R, Meyer WA. Volatile compounds of tufted hairgrass. Crop Sci. 2006;46:2575-80.

5. Scala A, Allmann S, Mirabella R, Haring MA, Schuurink RC. Green leaf volatiles: a plant's multifunctional weapon against herbivores and pathogens. Int J Mol Sci. 2013;14(9):17781-811.

6. Engelberth J, Alborn HT, Schmelz EA, Tumlinson JH. Airborne signals prime plants against insect herbivore attack. Proc Natl Acad Sci USA. 2004;101(6):1781-5

7. Scala A, Mirabella R, Mugo C, Matsui K, Haring MA, Schuurink RC. E-2-Hexenal promotes susceptibility to Pseudomonas syringae by activating jasmonic acid pathways in Arabidopsis. Front Plant Sci. 2013;4:74.

8. Baldwin IT. Plant volatiles. Curr Biol. 2010;20:R392-7. https://doi. org/10.1016/j.cub.2010.02.052.

9. Dong F, Fu X, Watanabe N, Su X, Yang Z. Recent advances in the emission and functions of plant vegetative volatiles. Molecules. 2016;21(2):124.

10. Lee K, Seo PJ. Airborne signals from salt-stressed Arabidopsis plants trigger salinity tolerance in neighboring plants. Plant Signal Behav. 2014;9(3):e28392.

11. Holopainen JK, Gershenzon J. Multiple stress factors and the emission of plant VOCs. Trends Plant Sci. 2010;15(3):176-84.

12. Engelberth J, Alborn HT, Schmelz EA, Tumlinson JH. Airborne signals prime plants against insect herbivore attack. Proc Natl Acad Sci USA. 2004:101:1781-5

13. Kessler A, Halitschke R, Diezel C, Baldwin IT. Priming of plant defense responses in nature by airborne signaling between Artemisia tridentata and Nicotiana attenuata. Oecologia. 2006;148(2):280-92.

14. Heil M, Bueno JC. Within-plant signaling by volatiles leads to induction and priming of an indirect plant defense in nature. Proc Natl Acad Sci USA. 2007;104(13):5467-72.
15. Frost CJ, Mescher MC, Carlson JE, De Moraes CM. Plant defense priming against herbivores: getting ready for a different battle. Plant Physiol. 2008;146:818-24

16. Karban R, Shiojiri K, Huntzinger M, McCall AC. Damage-induced resistance in sagebrush: volatiles are key to intra-and interplant communication. Ecology. 2006;87(4):922-30.

17. Shiojiri K, Ozawa R, Matsui K, Sabelis MW, Takabayashi J. Intermittent exposure to traces of green leaf volatiles triggers a plant response. Sci Rep. 2012;2:378. https://doi.org/10.1038/srep00378.

18. Dombrowski JE, Hind SR, Martin RC, Stratmann JW. Wounding systemically activates a mitogen-activated protein kinase in forage and turf grasses. Plant Sci. 2011;180:686-93.

19. Dombrowski JE, Martin RC. Green leaf volatiles, fire and nonanoic acid activate MAPkinases in the model grass species Lolium temulentum. BMC Res Notes. 2014;7(1):807.

20. Sinha AK, Jaggi M, Raghuram B, Tuteja N. Mitogen-activated protein kinase signaling in plants under abiotic stress. Plant Signal Behav. 2011:6(2):196-203.

21. Taj G, Agarwal P, Grant M, Kumar A. MAPK machinery in plants: recognition and response to different stresses through multiple signal transduction pathways. Plant Signal Behav. 2010;5(11):1370-8.

22. Cristina MS, Petersen M, Mundy J. Mitogen-activated protein kinase signaling in plants. Ann Rev Plant Biol. 2010;61:621-49.

23. Fiil BK, Petersen $K$, Petersen M, Mundy J. Gene regulation by MAP kinase cascades. Curr Opin Plant Biol. 2009;12:615-21.

24. Dombrowski JE, Martin RC. Abiotic stresses activate a MAPkinase in the model grass species Lolium temulentum. J Plant Physiol. 2012;169:915-9.

25. Ichimura K, Mizoguchi T, Yoshida R, Yuasa T, Shinozaki K. Various abiotic stresses rapidly activate Arabidopsis MAP kinases ATMPK4 and ATMPK6. Plant J. 2000;24(5):655-65.

26. Hassan MN, Zainal Z, Ismail I. Green leaf volatiles: biosynthesis, biological functions and their applications in biotechnology. Plant Biotechnol J. 2015:13(6):727-39.

27. Matsui K. Green leaf volatiles: hydroperoxide lyase pathway of oxylipin metabolism. Curr Opin Plant Biol. 2006:9(3):274-80.

28. Hirao T, Okazawa A, Harada K, Kobayashi A, Muranaka T, Hirata K. Green leaf volatiles enhance methyl jasmonate response in Arabidopsis. J Biosci Bioeng. 2012;114(5):540-5.

29. Suzuki N, Koussevitzky S, Mittler RO, Miller GA. ROS and redox signalling in the response of plants to abiotic stress. Plant Cell Environ. 2012;35(2):259-70.

30. Miller G, Schlauch K, Tam R, Cortes D, Torres MA, Shulaev V, Dangl JL, Mittler R. The plant NADPH oxidase RBOHD mediates rapid systemic signaling in response to diverse stimuli. Sci Signal. 2009;2(84):ra45.

31. Frost CJ, Appel HM, Carlson JE, De Moraes CM, Mescher MC, Schultz JC. Within plant signalling via volatiles overcomes vascular constraints on systemic signalling and primes responses against herbivores. Ecol Lett. 2007;10(6):490-8

\section{Submit your next manuscript to BioMed Central and we will help you at every step:}

- We accept pre-submission inquiries

- Our selector tool helps you to find the most relevant journal

- We provide round the clock customer support

- Convenient online submission

- Thorough peer review

- Inclusion in PubMed and all major indexing services

- Maximum visibility for your research

Submit your manuscript at www.biomedcentral.com/submit
Ciomed Central 